\title{
Inhibition between channels selective to contour orientation and wavelength in the human visual system
}

\author{
WILLIAM LOVEGROVE \\ University of Tasmania, Sandy Bay, Hobart, Tasmania, Australia 7005
}

\begin{abstract}
Recent studies have demonstrated inhibition between channels selective to contour orientation in the human visual system. On the basis of adaptation studies, it has also been suggested that the human visual system contains channels jointly responsive to both contour orientation and wavelength. The present paper investigates inhibition between such channels. Two experiments demonstrated that, with simultaneous presentation of a center vertical target grating and a concentric surround grating, the threshold and the apparent orientation of the center grating depended on the relative orientations of the two gratings and also on whether they were viewed in the same or in different colored light. Color selectivity in both experiments was found across a wider range of angular separations than has generally been reported for successive presentation of the two stimuli. These results suggest inhibition between channels selective to combinations of contour orientation and wavelength in the human visual system.
\end{abstract}

McCollough (1965) found that orientation-specific color aftereffects could be induced by displaying alternately a horizontal grating in blue light and a vertical grating in orange light. When the gratings were subsequently viewed in white light, subjects reported that horizontal lines appeared orange and vertical lines blue. Two related types of colororientation aftereffects have subsequently been reported. In the first, a vertical line appears maximally tilted counterclockwise following exposure to clockwise tilted lines when the inspection and test patterns are the same color. The magnitude of the aftereffect is significantly reduced when the inspection and the test lines differ in color (Held \& Shattuck, 1971; Lovegrove \& Over, 1973). In the second class of aftereffect, the threshold for a vertical target grating is significantly higher following exposure to a vertical grating when both inspection and test grating are seen in the same color than when seen in different colored light (Lovegrove \& Over, 1973; May, 1972). Similar effects have also been demonstrated with contour spatial frequency (Breitmeyer \& Cooper, 1972; Stromeyer, 1972) and direction of contour motion (Favreau, Emerson, \& Corballis, 1972; Lovegrove, Over, \& Boerse, 1972).

It should be noted that not all reported experiments have demonstrated color selectivity in contour-threshold experiments (Maudarbocus \& Ruddock, 1973; Timney, Gentry, Skowbo, \& Morant, 1976). It has been argued previously that

Requests for reprints should be sent to William Lovegrove, Department of Psychology, University of Tasmania, G.P.O. Box 252c, Hobart, Tasmania, Australia 7005. the outcome of such experiments depends on whether the color and contour orientation information are both presented to the same or to different eyes (Over \& Wenderoth, 1974). The paper by Timney et al. (1976) is an exception to this argument.

Two types of explanation have been offered for these spatial-chromatic (or contingent) aftereffects. The first general account hypothesizes neural detectors sensitive to both orientation and wavelength (Held \& Shattuck, 1971; McCollough, 1965; Potts \& Harris, 1975). The assumption is that there are, for example, separate channels for red-vertical and green-vertical lines. During exposure to red vertical gratings, only neural analyzers tuned to both vertical contours and red are excited. Because these analyzers are suppressed for a period of time following exposure, those neural analyzers sensitive to green verticals will contribute relatively more after inspection than before. This imbalance has been assumed to account for the various effects demonstrated.

Murch (1976), in contrast, has proposed that contingent aftereffects may best be accounted for in terms of classical conditioning. This position is supported by experiments on the temporal properties of contingent aftereffects (MacKay \& Mackay, 1974; Murch, 1976). With long adaptation durations, some of these effects persist for days or even weeks. An important question concerns the nature of spatial-chromatic effects when the colors and contours are presented for short durations in a simultaneous, rather than a successive, contrast situation. This situation should minimize possibilities for learning to occur but provide ample time for inhibi- 
tory processes to operate as outlined below.

It is known that, with achromatic stimuli, threshold elevation and perceptual distortions occur with simultaneous presentation of two gratings at different orientations. Simultaneous orientation illusion effects have been investigated by Blakemore, Carpenter, and Georgeson (1970) and Wallace (1969). Mackay (1973) has demonstrated a parallel spatial-frequency illusion. Klein, Stromeyer, and Ganz (1974) investigated the effect of a surround grating on both the perceived orientation and the threshold of a center vertical target grating with simultaneous presentation of the two gratings. They demonstrated the tilt illusion under such conditions but found no threshold elevation. In contrast, Tolhurst and Thompson (1975) investigated these effects further and were able to demonstrate both a change in the apparent orientation and the threshold of a vertical test grating in the presence of a surround grating tilted $12^{\circ}$ from vertical. The threshold elevation (which was not demonstrated by Klein, Stromeyer, \& Ganz, 1975) was found only when the whole of the test grating was close to the inducing grating. It was argued by Tolhurst and Thompson (1975) that their results could be explained in terms of inhibition between channels or detectors responding to similar orientations and subserving similar parts of the visual field. This proposal has received further support by Thomas and Shimamura (1975), who found threshold elevation when subjects detected stimuli which simultaneously activated channels tuned to two different orientations. They attributed this threshold elevation to inhibition between channels tuned to different orientations.

Two experiments reported in the present paper examine color selectivity in the tilt illusion and in simultaneous orientation masking. If inhibition occurs between channels sensitive to contour orientation and wavelength, it should be possible to demonstrate a change both in the apparent orientation and in the detection threshold of a test grating which is contingent upon the color and orientation relationship between the center target and the surround induction grating. In addition, the present experiments concern the time courses of development of spatialchromatic effects.

\section{EXPERIMENT 1}

\section{Method}

Subjects. Thirteen undergraduate students with normal or corrected-to-normal vision were tested. All subjects were screened for anomalies in color vision by the Ishihara test for color blindness.

Apparatus and Procedure. The tilt illusion was measured by determining the orientation at which the test grating was judged to be vertical as a function of both the wavelength and orientation of a concentric surround grating. Both the surround inducing field and the center target field could be illuminated in red light
(Wratten filter 26) and green light (Wratten filter 55). Surround grating orientations of $0^{\circ}$ (vertical), $15^{\circ}, 30^{\circ}, 45^{\circ}$, and $75^{\circ}$ clockwise from vertical were used. In addition, a blank surround annulus of the same wavelength and space-average luminance was also used. The surround inducing annulus had an inside diameter of $0.75^{\circ}$ and an outside diameter of $3.0^{\circ}$ of visual angle. The test stimulus was a circular grating whose diameter subtended $0.75^{\circ}$ visual angle. Both gratings were square wave with spatial frequency of $6 \mathrm{c} / \mathrm{deg}$ and a Michelson contrast of 0.6. The spaceaverage luminance of the surround grating was always maintained at $2.2 \mathrm{~cd} / \mathrm{m}^{2}$ and that of the test grating at $1.0 \mathrm{~cd} / \mathrm{m}^{2}$. Stimuli were presented monocularly in a Scientific Prototype three-field tachistoscope (Model GB).

Seven subjects were tested with a vertical test grating in red light and six with the test grating in green light. Judgments of vertical for each subjects were determined with each of the five inducing grating orientations and the blank surround displayed in red and green light. Seven of the subjects saw the inducing grating in red light first and six in green light first. The order of presentation of induction grating orientations was counter-balanced across subjects, and for each subject this order was held constant across the two induction wavelengths.

On each trial, the subject viewed a dim, red fixation point in the center of a dimly illuminated field of $1.0 \mathrm{~cd} / \mathrm{m}^{2}$. When the subject pressed a button, the adaptation field was replaced by two fields, one containing the surround induction grating and the other the center test grating. Both gratings were exposed for $1 \mathrm{sec}$. The subject was required to judge whether the test grating appeared tilted to the right or to the left of the vertical; he was not allowed to report that the line appeared vertical. Under a given condition, the target grating was presented at the objective vertical on the first trial, and on subsequent trials, its orientation was varied in $1^{\circ}$ steps in accord with a double random staircase procedure until seven reversals in tilt judgment from left to right had occurred.

The test grating was testing as having appeared vertical at the orientation midway between the values on which the subject gave opposite tilt judgments. The illusion reflected the difference between this measure of apparent vertical and the baseline data obtained when the test grating was judged in the presence of the blank surround of the same wavelength and space-average luminance as the contoured surround grating.

\section{Results and Discussion}

Illusion scores were determined for each subject as outlined above. Inspection of the scores revealed no differences between scores obtained with red target and those obtained with a green target, so, for the analysis, these two groups of scores were combined. Mean illusions for the different inspection conditions are shown in Figure 1.

An analysis of variance showed that the mean illusion varied as a function of the orientation of the induction gratings $[F(4,48)=24.47, p<.01]$ and as a function of the color relationship between the surround and target $[F(1,12)=9.80, p=.01]$. The interaction between the surround orientation and the color relationship between the center and surround was nonsignificant $[F(4,48)=0.99]$. When the individual means were compared by Duncan's new multiple range test, it was found that a significant illusion occurred with surround orientations of $15^{\circ}$ and $30^{\circ}$, both when the color relationship between the center and the surround was the same and when it was different. Significantly greater illusion was 


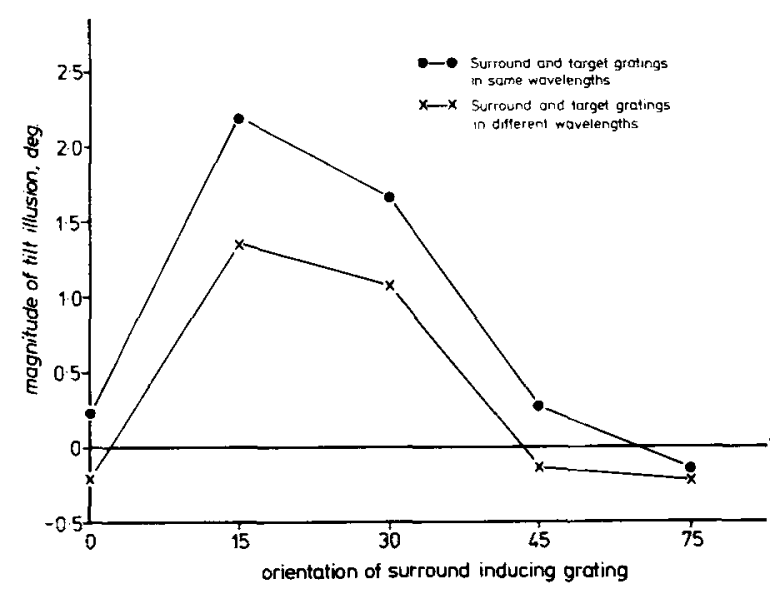

Figure 1. Mean illusion values for different orientations of the surround grating and combinations of surround and target grating colors.

found, however, when the surround and center were displayed in the same colored light than when they were displayed in different colored light. No other surround and condition produced a significant illusion. These results suggest that the inhibition proposed by Tolhurst and Thompson (1975) to occur between orientation sensitive channels also operates between channels selectively sensitive to contour and wavelength, producing color selectivity in the tilt illusion.

\section{EXPERIMENT 2}

Response properties of visual detectors have also been studied by threshold elevation paradigms (Blakemore \& Nachmias, 1971; Tolhurst \& Thompson, 1975). It is known that exposure to one grating impairs detection of another grating as a function of relative orientation and wavelength when the two gratings are presented successively and viewed by the same eye (Lovegrove \& Over, 1973; May, 1972). In view of Tolhurst and Thompson's demonstration of threshold elevation of a vertical test grating as a function of the orientation of a surround grating, Experiment 2 investigated color sensitivity in simultaneous contour orientation masking.

\section{Method}

Subjects. Ten undergraduate students with normal or correctedto-normal vision were used as subjects. All subjects were screened for anomalies in color vision by the Ishihara test for color blindness.

Apparatus and Procedure. A simultaneous masking paradigm was used. On each trial, a surround inspection grating and a center target grating were shown with simultaneous onset. The surround was shown for $1 \mathrm{sec}$ and the duration of the target stimulus was the dependent variable. A vertical grating target displayed in red or green light was used as the test stimulus on half the presentations, and a blank field of the same wavelength and space-average luminance was presented on the other half of the trials. Care was taken to ensure that the space-average luminance of the targets remained constant in the presence of the blank and grating surrounds. This was done by measuring the space-average luminance of the targets in the presence of the various surrounds both before and after each experimental session. Spaceaverage luminance was determined by averaging a number of photometer readings. The subject's task was to identify which test stimulus had been shown. The experiment measured the period of display needed for $75 \%$ accuracy in judgments under different inspection conditions. Surround orientations of $0^{\circ}$ (vertical), $15^{\circ}, 30^{\circ}, 45^{\circ}$, and $75^{\circ}$ were used, while the target grating remained vertical. A circular target of diameter $0.75^{\circ}$ visual angle and a surround annulus with an inner diameter of $0.75^{\circ}$ and an outer diameter of $3.0^{\circ}$ visual angle were used. These dimensions were chosen on the basis of Tolhurst and Thompson's (1975) results. Under these conditions, the entire test pattern should be affected by the surround grating. Other properties of the surround and target gratings were as described for Experiment 1.

Five subjects were tested with a vertical test grating in red light and five with the test grating in green light. Each subject was tested, in separate sessions, with the surround displayed in red and green light and at all orientations. Half the subjects saw the inducing grating in red light first and the other half in green light first. The order of presentation of induction grating orientations was counterbalanced across subjects and, for each subject, was held constant across the two color conditions. Viewing was always monocular.

Detection was measured by a blockwise tracking method (see Lovegrove \& Over, 1973). Under each inspection condition, the period of display was varied in ratio steps $(1,2,4,8,16 \ldots$ msec) over blocks of 12 trials (6 gratings and 6 blank presentations in random order) until the subject achieved $75 \%$ accuracy over a single block or bracketed this value between successive blocks. Detection was also measured when the test stimulus was shown surrounded by a homogeneous surround annulus matched in wavelength and space-average luminance with the appropriate grating surrounds.

\section{Results and Discussion}

The threshold for contour detection under each condition was taken as the period the target needed to be exposed for $75 \%$ accuracy in differentiation of line and blank trials. For each subject, a masking ratio was calculated for each combination of surround orientation and color and center color by dividing the threshold measured with exposure to the inducing grating by the threshold found when the homogeneous field was shown in place of the surround grating. A ratio greater than 1.0 indicated that the target line was less detectable in the presence of a contoured surround than in the presence of a homogeneous surround.

The mean masking ratios are shown in Figure 2. These were analyzed as a two-way analysis of variance with repeated measures on both factors: color relationship between center and surround (same or different) and orientation of surround grating. Inspection of the scores showed that masking did not differ as a function of target color, so the scores for these two groups were combined for analysis.

It is noticeable that the general level of masking in this experiment, with nonoverlapping masks and targets, is significantly less than that reported for 


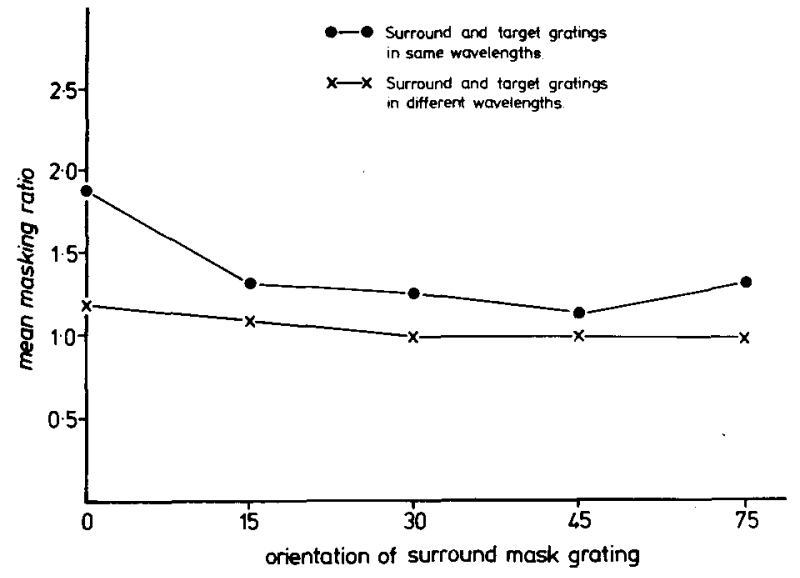

Figure 2. Mean masking ratios for different orientations of the surround grating and combinations of surround and target grating colors.

forward masking with overlapping mask and target stimuli (Lovegrove \& Over, 1973).

The analysis of variance showed that masking varied as a function of the orientation of the induction gratings $[F(4,36)=3.91, p<.01]$ and the color relationship between the center and surround gratings $[F(1,9)=12.42, p<.01]$. In addition, the interaction between surround orientation and color relationship between the center and surround was significant $[F(4,36)=4.01, p<.01]$. Multiple comparisons between the means based on Duncan's new multiple range test showed that masking was significantly greater when mask and target were displayed in the same color than when displayed in different colored light with surround orientations of vertical, $15^{\circ}, 30^{\circ}$, and $75^{\circ}$. When masks and target were presented in the same colored light, a vertical mask produced significantly greater masking than did any other mask orientation.

The general result was that, while slight but significant threshold elevation was found with surround and target in the same colored light (especially with a vertical mask), very little masking occurred when mask and target were presented in different colored light.

\section{GENERAL DISCUSSION}

The present results have demonstrated that both the perceived orientation and detection threshold of a center, vertical target grating are dependent upon the color and orientation of a surround grating. It is proposed that these results may be accounted for in terms of inhibition between channels selectively sensitive to both contour orientation and wavelength. A similar suggestion based on results obtained with achromatic stimuli has been made by Tolhurst and
Thompson (1975) and Thomas and Shimamura (1975). It has been noted that in both experiments color selectivity was found to occur over a wider range of angular separations between surround and target stimuli than has been reported for successive presentation of the two stimuli (Lovegrove \& Over, 1973; May, 1972). Similar results have been reported for achromatic stimuli (Kulikowshi, 1972; Lovegrove, 1976).

It has recently been suggested that some properties of color-spatial aftereffects may best be explained in terms of learning, as many of the temporal characteristics of such effects resemble learning phenomena (Murch, 1976; Skowbo, Timney, Gentry, \& Morant, 1975). The present demonstration of color selectivity in the simultaneous presentation of the inducing and test stimuli suggests that at least some color-spatial effects may be most simply explained in terms of inhibition between channels sensitive to combinations of contour orientation and wavelength. Possibly it is premature to consider all types of spatialchromatic effects as constituting a single class of effects. One reason for doing this has been the far longer persistence of spatial-chromatic aftereffects (Mayhew \& Anstis, 1972). It has now been demonstrated that, with the motion aftereffect (Kalfin \& Locke, 1972) and with contour-orientation-specific threshold elevation (Heggelund \& Hohmann, 1976), longer adaptation periods produce long-lasting effects. These demonstrations, that simple aftereffects may persist for some hours following long adaptation periods and that contingent effects may occur in simultaneous contrast situations, make the distinction between simple and contingent aftereffects unclear. This is even more apparent when it is considered that the adaptation durations used in contingent aftereffect experiments have normally been far longer than those used in simple aftereffect experiments. Before a distinction can be made between the two types of aftereffects, perhaps more should be known about the development and decay functions of all the relevant effects.

\section{REFERENCES}

Blakemore, C., Carpenter, R., \& Georgeson, M. Lateral inhibition between orientation detectors in the human visual system. Nature, 1970, 228, 37-39.

Blakemore, C., \& Nachmias, J. The orientation specificity of two visual aftereffects. Journal of Physiology, 1971, 213, 157-174.

Breitmeye R, B. G., \& Cooper, L. A. Frèquency-specific color adaptation in the human visual system. Perception \& Psychophysics, 1972, 11, 95-96.

Favreau, O, Emerson, V., \& Corballis, M. C. Movement aftereffects contingent on color. Science, 1972, 176, 78-79.

Heggelund, P., \& Hohmann, A. Long-term retention of the "Gilinsky-effect." Vision Research, 1976, 16, 1015-1017.

Held, R., \& Shattuck, S. R. Color and edge-sensitive channels 
in the human visual system: Tuning for orientation. Science, $1971,174,314-316$.

Kalfin, K., \& Locke, S. Evaluation of long term visual afterimage following monocular stimulation. Vision Research, 1972, 12, 359-361.

Klein, S., Stromeyer, C. G., \& Ganz, L. The simultaneous spatial frequency shift: A dissociation between the detection and perception of gratings. Vision Research, 1974, 14, 1421-1432.

Kulikowski, J. J. Orientational selectivity of human binocular and monocular vision revealed by simultaneous and successive masking. Journal of Physiology, 1972, 226, 67-69.

LOVEgRove, W. J. Inhibition in simultaneous and successive contour interaction in human vision. Vision Reseanch, 1976, 16, 1519-1521.

Lovegrove, W. J., \& Over, R. Color selectivity in orientation masking and aftereffect. Vision Research. 1973, 13, 895-902.

Lovegrove, W. J., Over, R., \& Broerse, J. Color-selectivity in motion aftereffects. Nature, 1972, 238, 334-335.

McCollough, C. Color adaptation of edge-detectors in the human visual system. Science, $1965,149,1115-1116$.

MACKAY. D. M. Lateral interaction between neural channels sensitive to texture density. Nature, 1973, 245, 159-161.

Mackay, D., \& MACKaY. V. What causes decay of patterncontingent chromatic aftereffects? Vision Research, 1974, 14, $1285-1288$.

MaUdarbocus, A. Y., \& Ruddock, K. H. The influence of wavelength on visual adaptation to spatially periodic stimuli. Vision Research, 1973, 13, 993-998.

MAY, J. G. Chromatic adaptation of orientation and sizespecific visual processes in man. Vision Research, 1972, 12, $1509-1517$.
MaYHEW, J. E. W., \& ANstis, S. M. Movement aftereffects contingent on color, intensity, and pattern. Perception \& Psychophysics, 1972, 12, 77-85.

Murch, G. M. Classical conditioning of the McCollough effect: Temporal parameters. Vision Research, 1976, 16, 615-619.

OVER, R., \& WENDEROTH, P. Is spatial masking selective to wavelength? Vision Research, 1974, 14, 157-158.

Potrs, M., \& Harris, J. Movement aftereffects contingent on the color or pattern of a stationary surround. Vision Research, $1975,15,1225-1230$.

Skowbo, D., Timney, B. N., Gentry, T. A., \& Morant, R. B. McCollough effects: Experimental findings and theoretical accounts. Psychological Bulletin, 1975, 82, 497-510.

STROMEYER, C. F. Edge-contingent color aftereffects: Spatial frequency selectivity. Vision Research, 1972, 12, 717-733.

Thomas, J. P., \& Shimamura, K. K. Inhibitory interaction between visual pathways tuned to different orientations. Vision Research, 1975, 15, 1313-1380.

Timney, B. N., Gentry, T. A., Skowbo, D., \& Morant, R. B. Threshold elevation following adaptation to coloured gratings. Vision Research, 1976, 16, 601-607.

TolhuRst, D. J., \& Thompson, P. G. Orientation illusions and aftereffects: Inhibition between channels. Vision Research, 1975, 15, 967-972.

Wallace, G. K. The critical distance of interaction in the Zöllner illusion. Perception \& Psychophysics, 1969, 5, 261-264.

(Received for publication April 23, 1976; revision accepted January $10,1977$. 